\title{
VIOLÊNCIA E PROFILAXIA: OS PREVENTÓRIOS PAULISTAS PARA FILHOS DE PORTADORES DE HANSENÍASE*
}

\author{
Yara Nogueira Monteiro**
}

\begin{abstract}
RESUMO: Esse artigo analisa como que a prática do isolamento compulsório dos pacientes de hanseníase no Estado de São Paulo contribuiu para que o estigma da hanseniase atingisse pessoas que nunca portaram a doença, como foi o caso das crianças sadias filhas de portadores de hanseniase. Discute como que os ideais eugênicos contribuiram para a formação de uma postura médica que, mesmo a revelia dos progressos científicos e das recomendações internacionais, perpetuaram medidas de discriminação e segregação dessas crianças. Demonstra como estas acabaram por se tornar portadoras de um "estigma congênito" que as acompanharia por toda a vida e como isto resultou na diminuição de possibilidades de vida, obrigando-as a esconder sua situação de internas ou egressas de Preventório se quisessem competir em igualdade de condições quando da procura de emprego ou no estabelecimento de relações sociais. Analisa ainda a vida dentro dos Preventórios, a separação da família e o quotidiano de centenas de vidas moldadas dentro de estruturas de controle, nas quais a violência e o arbítrio se faziam em nome de uma visão distorcida de profilaxia.
\end{abstract}

Palavras-chave: estigmatização, marginalidade, hanseniase, preventórios, políticas de saúde

* Realizado com base em um dos capitulos da Tese de Doutorado "Da Maldição Divina a exclusão social: um estudo da Hanseniase em São Paulö. FFLCH/USP, 1995.

** Mestre em História Social pela FFLCH/USP. Doutora en História Social pela FFICH/USP, Pesquisadora Cientifica do Instituto de Saúde. 
Ao se estudar a história dos grupos estigmatizados, torna-se imprescindível o estudo daqueles que, por uma razão qualquer, foram tidos como "leprosos" e portanto, como tal, sofreram medidas de exclusão. A trajetória dessa moléstia permite verificar que parte da visão medieval acerca da doença e seu de seu portador conseguiu chegar até nosso século e que, malgrado o avanço da ciência, medidas de exclusão continuaram a ser praticadas em nome da defesa do bem estar da coletividade. Mesmo após a descoberta de uma terapêutica eficaz contra a doença, medidas de exceção, segregação e violência continuaram a ser praticadas contra o doente, e estas também alcançaram seus familiares ${ }^{1}$.

No Brasil, a revelia das recomendações internacionais que desde a década de vinte já desaconselhavam o isolamento do doente, a prática profilática adotada foi a do isolamento compulsório, o que contribuiu para alicerçar na população conceitos errôneos já existentes sobre a doença.

Essa prática permitiu que o estigma da hanseníase atingisse pessoas que nunca portaram a doença, como foi o caso das crianças sadias filhas de hansenianos, que acabaram por se tornar portadoras de um "estigma congênito" que as acompanharia por toda a vida, diminuindo suas possibilidades de vida e obrigando-as a esconder sua situação, de internas ou egressas de Preventório, se quisessem competir em igualdade de condições quando da procura de emprego ou no estabelecimento de relações sociais.

A preocupação com a criança sadia, filha de hansenianos, se evidenciou no Brasil principalmente a partir de fins da década de vinte, quando apareceram os primeiros Preventórios. Essa preocupação coincidiu com uma nova dimensão que a questão da infância vinha assumindo na área médica na Europa, com reflexos em nosso país, quando se verifica, por um lado, a preocupação com a infância sadia, e por outro o crescimento das idéias eugênicas.

Um rápido retrospecto histórico permite observar que a partir de fins do século XIX a infância começara a ser alvo de maiores atenções, e objeto de estudo, por parte da ciência. Essa tendência foi se acentuando durante as primeiras décadas de nosso século, quando se organizaram os primeiros eventos científicos internacionais söbre o tema. Em 1913 realizou-se o $1^{\circ}$ Congresso Internacional de Proteção à Infância na Europa, que foi sediado na Bélgica; nas Américas o $1^{\circ}$ Congresso Americano da Criança foi organizado em 1916, na Argentina. Estes eventos constituíram-se em marcos precursores, tendo sido sucedidos por uma série de outros.

\footnotetext{
1. No inicio da década de quarenta foi descoberto o tratamento através das sulfonas. Com este, em poucos meses de tratamento o doente tinha sua hasiloscopia negativada. o que significava que ele perdia sua condição de inlectante e portanto deixava de representar uma ameaça à coletividade, podendo conviver normalmente em sociedade. Esse fato representou um marco revolucionário na trajetória dessa doença, que o ano de 1943 passou a se constituir num marco.
} 
No Brasil assistiu-se ao reflexo desse movimento, como por exemplo o $1^{\circ}$ Congresso Brasileiro de Proteção à Infância, realizado no Rio de Janeiro em 1922, que contou com a participação de importantes nomes da área médica e dos círculos governamentais, e cujo discurso de abertura foi realizado pelo Ministro do Interior ${ }^{2}$. Esse evento foi organizado como parte das comemorações do centenário da independência. O estudo das publicações dos congressos médicos da época demonstra que a temática da infância, com fortes conotações eugênicas, estava adquirindo novos contornos no Brasil, sendo apresentada dentro de perspectivas mais amplas. A criança deixava de ser vista como um problema familiar para ser vista como uma questão de ordem social:

"Uma criança que se perde, material ou moralmente (...) significa uma força que se perde para a sociedade" (BARBOSA, 1925)

\section{FILHOS SADIOS DE PAIS DOENTES: O ALIJAMENTO}

Durante a década de vinte, observou-se no Brasil uma marcante preocupação com os ideais eugênicos, que encontravam grande aceitação em importantes segmentos da "intelligentzia" brasileira, em especial entre juristas e médicos. Estudos da época demonstravam ser a população brasileira escassa e doentia ${ }^{3}$. A doença passava a ser vista como ameaça à nacionalidade forte e a mortalidade infantil, figurava como sério obstáculo ao desenvolvimento da nação. O país passava por uma série de transformações que exigiam a adaptação da população às novas relações de produção. Pretendiase realizar alterações na sociedade, e para tal a criança era vista como tendo papel de extrema importância. Nesse sentido as propostas médicas, em especial as dos eugenistas, começaram a adquirir novas dimensões e contornos políticos.

Nesse contexto emergiu a problemática acerca da prole dos "leprosos". Muitos acreditavam que essas crianças já traziam em si uma "tara", o que influenciava no tipo de discurso e de soluções propostas, uma das quais era a de esterilização. Contudo, havia um fato concreto a ser equacionado, que era o desamparo daquele menor cujo núcleo familiar se desestruturara em conseqüência da internação de um ou de ambos os genitores.

Com a politica de internação em massa - adotada no Estado de São Paulo a partir de 1928 que passou a segregar compulsoriamente toda e qualquer pessoa portadora do Mal de Hansen - os menores infectados, tal como os adultos, eram internados nas instituições asilares. Todavia, a grande indagação era sobre o que fazer com crianças sadias que não tinham para onde ir. A orientação das autoridades era de que fossem entregues a seus

2. Nessa época as questões de saúde eram da órbita do Ministério da Justiça e Negócios Interiores.

3. Sobre ao assunto ver MONTEIRO (1995) - Parte III, cap. 2. "Eugenia e o discurso da Salvação da Raça". 
familiares, porém a prática demonstrou que o medo do contágio e o estigma que revestia a doença faziam com que dificilmente houvesse parentes dispostos a receber a criança.

"Compreende-se que o estigma acarretado pela lepra constitui o elemento número um para o ajuste dos menores; seus parentes recusam-se muitas vezes a recebê-los com receio de que eles também venham a adoecer, constituindo fonte de contágio para si mesmos e para seus próprios filhos." (CAMPOS \& BECHELLI, 1948)

A rigor esse problema não era da competência médica, entretanto a situação de vida dessas crianças era decorrente da adoção de uma determinada política sanitária.

Proliferavam discussões sobre a quem caberia a responsabilidade desses menores e até que ponto o Estado seria responsável pela saúde e educação dos mesmos. 0 médico passou a ser apresentado como sendo o "verdadeiro estadista do presente", e a medicina como tendo a missão de realizar a "salvação nacional" (SCHECHTMAN,1981).

\section{A INTERNAÇÃO EM MASSA E O DESAMPARO DO MENOR}

A implantação da política de internação compulsória, tanto no Brasil como em outros paises, acabou por gerar problemas sociais que causavam reflexos diretos no comportamento dos doentes. Uma das conseqüência do isolamento era a freqüente situação de desamparo familiar. Esse fator contribuiu para que muitos doentes optassem pelo não tratamento, ocultando-se dos Serviços Médicos ou optando por sua interrupção fugindo dos locais de isolamento. Isso resultava na continuidade dos focos de contágio, $\mathrm{O}$ que configurava poderoso entrave para a profilaxia do doença ${ }^{4}$.

Discussões eram travadas, em especial no corpo da classe médica, procurando descobrir soluções concretas para o problema. Essa situação levou Souza Araújo a realizar pesquisa sobre os procedimentos adotados pelos governantes de paises endêmicos com relação ao menor. O resultado desse trabalho, apoiado basicamente nos resultados apresentados na $2^{\circ}$ Conferência Internacional de Lepra realizada em Bergen no ano de 1909, foi apresentado em 1916 no ${ }^{\circ}$ Congresso Médico Paulista. Posteriormente, Souza Araújo escreveu um livro sobre o assunto, no qual demonstrava que a resolução do problema do menor era de extrema importância em qualquer tentativa de se equacionar os esforços profiláticos (SOUZA ARAUJO, 1929).

Os procedimentos adotados nos paises onde a hanseniase era endêmica podem ser divididos em dois grandes blocos: havia os que optaram por colocar os menores em estabelecimentos especiais, e havia os que optaram por dar condições para que as crianças pudessem continuar convivendo em núcleos familiares. No primeiro bloco destacam-se

4. A análise dos prontuários de doentes internados revela que grande parte dos motivos alegados para a fuga, dos locais de isolamento, era a tentativa de prover as necessidades familiares. 
governos que na época faziam parte de impérios coloniais, como Havaí, Índia e Filipinas. O Havaí, já em 1880, havia criado seu primeiro Preventório, para onde eram enviadas as crianças sadias; a Índia, desde fins do século XIX, se preocupava com essa questão e, a partir de 1886, já havia locais próprios para abrigá-las; o mesmo processo aconteceu nas Filipinas. Outros países adotaram diferentes práticas, mas que também retiravam o menor do convívio social, como por exemplo permitir que crianças sadias acompanhassem seus pais, e portanto fossem criadas dentro dos locais de isolamento.

No segundo bloco encontra-se a solução adotada pela Noruega. Nesse país, a partir da experiência ali desenvolvida, adotou-se um encaminhamento diferente. Os noruegueses demonstraram que a simples "internação" de um menor num Preventório resolvia o problema mais premente, que se constituía no desamparo e na eliminação do risco de contágio, contudo, não equacionava o problema da criança, isto devido aos desdobramentos apresentados, dentre eles graves sinais de desajustes sociais. Em vista disso, o Estado norueguês optou pela convivência do menor sadio no meio familiar, e para tanto fornecia ajuda financeira à família que recebesse a criança. A ajuda governamental era suficiente para manter toda uma família.

Entre os hansenólogos paulistas havia uma corrente que considerava a solução norueguesa como sendo a ideal. Discutia-se a situação das familias e das crianças, e entendia-se como sendo dever do Estado o controle da doença, assim como a ajuda financeira à família. Souza Araújo - na época Diretor do Serviço Nacional de Lepra - era um dos que não partilhava dessa postura, antes defendia como imperativa a segregação dos filhos de doentes, e para tanto propunha a construção de Preventórios. No Brasil essa discussão ainda se arrastaria por muitos anos, porém ao final foi a corrente segregacionista que acabou prevalecendo.

Com o passar dos anos foram surgindo preventórios por todo o território nacional, que aliás foram sendo construídos através da iniciativa particular e não com recursos governamentais, como foi o caso do Asilo de Santa Terezinha, em São Paulo, o primeiro do gênero a ser constituido e que se constituiria numa espécie de modelo que, de certa forma, seria seguido 5 .

Na década de trinta, a idéia que passou a imperar foi a de que toda e qualquer medida profilática deveria estar assentada no tripé constituído pelo Asilo, Dispensário e Preventório, cada qual desempenhando seu papel específico ${ }^{6}$. Dentro dessa ótica, os Preventórios desempenhariam papel preventivo, pois acreditava-se que a criança, por já ter

5. Por ocasião de sua inauguração, em 1926, a Índia já possuia estabelecimentos em número suliciente para abrigar 800 menores.

6. Os dispensários eram responsáveis pelo diagnóstico precoce da doença e pélo acompanhamento sistemático dos comunicantes visto que estes poderiam vir a desenvolver a doença constituindo os futuros focos de contaminação. O Asilo era o local de internação compulsória de toda e qualquer pessoa portadora do Mal de llansen. liresse ou não forma clinica infectante. 
tido contato com um foco da doença, ou simplesmente por ser filho de um genitor doente, teria mais condições de vir a desenvolver a doença e que, portanto, deveria ir para um local especialmente criado para recebê-la, onde seria examinada periodicamente. Com base nessa premissa, os filhos de pais hansenianos tiveram vedado seu direito de ingresso a outros internatos e, após ingressar num Preventório, encontravam sérios problemas para sair, pois o próprio Regimento Interno dos Preventórios, em seu artigo primeiro, previa que o menor não poderia sair durante os seis primeiros anos de permanência.

Desta forma, dentro da ótica adotada com relação ao esforço profilático, o Preventório adquiria uma nova dimensão e era visto como medida fundamental que garantiria o êxito profilático da política de isolamento compulsório.

Dentre as vozes divergentes, que se posicionavam contra a construção de Preventórios, temos Alice Tibiriçá e Floriano Lemos ${ }^{7}$. Esse último criticava freqüentemente o modelo de assistência a lepra implantado em São Paulo, inclusive a existência de Preventórios. Em artigo publicado em 1939, ele conseguiu demonstrar com grande perspicácia o problema que o modelo iria gerar no futuro e explicitou, de forma clara, suas preocupações com o destino dessas crianças que, embora sadias, seriam condenadas à exclusão social:

(...) não acreditamos que essas criancinhas (...) amanhã quando adultas tenham fácil acesso em nossos lares, em nossa sociedade. Estarão condenadas a constituir um grupo à parte e, como párias, terão que viver à margem da nossa sociedade. Serão expensionistas do Asylo Santa Terezinha!

Senão no physico, pelo menos moralmente carregarão para sempre a herança paterna.

Se em face das leis da eugenia não são elementos recomendáveis se-lo-ão como factores econômicos positivos?

(...) Maldirão por certo a nossa falsa caridade que permitiu a sua existência (LEMOS, 1939)

O autor era partidário da criação de granjas, onde as crianças poderiam ser criadas juntamente com seus familiares ${ }^{8}$.

7. Alice Tibiriçá teve atuaçào destacada no campo da hanseniase nas décadas de vinte e trinta: Floriano l.emos foi professor da Faculdade de Medicina do Rio de Janeiro e eserevia artigos em jornais cariocas.

8. Alice Tibiriçá era também partidária da construção de granjas, pois acreditava que estas contribuiriam para manter o núcleo familiar. I/ma granja chegou a ser construida nas proximidades da cidade de Bauru. contudo, as desavenças existentes entre Alice e o Departamento de Protilaxia da lepra levaram a desativaçào do projeto. Sobre o assunto ver TIBIRIC Á (19+8). 


\section{A PROBLEMÁTICA DA LOCALIZAÇÃO DOS PREVENTÓRIOS.}

A partir, principalmente dos anos trinta, Preventórios começaram a ser construídos em diferentes pontos do pais. Contudo, embora houvesse uma preocupação latente por parte de órgãos oficiais com relação à problemática desses menores, não se verificou qualquer ação concreta do Estado e todo o esforço de construção e administração, com uma única exceção, acabou sendo realizado pela iniciativa privada. Nessa área se destacou a Federação das Sociedades de Assistência aos Lázaros que, segundo Souza Campos, em muitos Estados desenvolveu trabalhos melhores do que os dos próprios hospitais e ambulatórios que contavam com ajuda oficial (SOUZA CAMPOS \& BECHELLI, 1948).

Aos poucos, apesar de haver atritos, verifica-se surgir certa identidade entre a postura governamental e a particular. A Federação das Sociedades de Assistência aos Lázaros havia elaborado um regulamento interno para seus estabelecimentos que acabou por ser adotado pelo Departamento Nacional de Saúde. Este reconheceu a experiência desenvolvida pela Federação e houve por bem convidá-la para que, juntamente com os técnicos do Departamento Nacional de Saúde, elaborassem um regimento único que pudesse ser adotado para que todos os Preventórios do país tivessem atuação semelhante.

O artigo primeiro do Regimento Interno dos Preventórios apresentava como sendo objetivo dessas instituições:

"... acolher, manter, educar e instruir menores sadios filhos de conviventes de doentes de lepra, desde que não tenham parentes idôneos que queiram assumir esse encargo e que disponham de recursos para educá-los e mantê-los sob a vigilância das autoridades sanitárias competentes".

Além do controle profilático e da formação educacional, figuravam como objetivos do Preventório a assistência ao menor com relação a seu desenvolvimento físico e religioso.

Previa-se o atendimento de crianças de todas as idades, desde o recém nascido, que seria separado de sua mãe imediatamente após o parto, como também daquelas que já tivessem sido expostas ao contágio, em razão de terem convivido com familiares doentes.

Com relação à localização geográfica dos Preventórios, observa-se ter havido posturas diferentes acerca dessa questão. Havia os que pretendiam instalá-los nas proximidades dos asilos; outros preferiam colocá-los em locais afastados da cidade; e uma terceira postura defendia o direito da construção de Preventórios dentro das zonas urbanas.

O primeiro grupo alegava que a proximidade do Preventório com o asilo facilitaria 0 atendimento médico especializado e, além disso, possibilitaria a realização de pesquisas sobre a evolução da doença na infância. Alegavam ainda que os pais ficariam mais próximos dos filhos, fator que contribuiria para a diminuição das fugas dos asilos. Essa postura 
apresentava uma série de inconvenientes, dentre elas a influência que as instituições de isolamento, fatalmente, exerceriam sobre o Preventório, podendo inclusive resultar numa espécie de absorção do menor pelo maior. Haveria ainda o risco de associação, por parte da população, entre as duas instituições. Isto acarretaria problemas para as crianças, que seriam abertamente identificadas com a doença, ou seja, o estigma que atingia os internos dos asilos alcançaria igualmente as crianças. Durante a $1^{\circ}$ Conferência Nacional de Assistência ao Lázaro, realizada no Rio de Janeiro em 1939, essa questão foi alvo de debates. Dentre os inconvenientes, foi ressaltado o aspecto disciplinar, posto que a proximidade facilitaria ou mesmo incentivaria o doente a infringir as normas existentes para estar com seus filhos.

Quanto à segunda postura, as principais críticas se centravam no fato de que a construção de Preventórios em locais afastados de centros populacionais geraria uma série de problemas, tanto na formação educacional do interno, como no relacionamento social da criança. De acordo com Nelson de Souza Campos, não se poderia alegar motivos de ordem profilática ou higiênica para servir de entrave à construção de Preventórios no perímetro urbano, visto que as pessoas ali internadas eram sadias ${ }^{9}$.

A terceira corrente era partidária da construção de Preventórios dentro das zonas urbanas das cidades. Aconselhava que fossem levados em consideração, na escolha do local, fatores como: salubridade do clima, meios de comunicação e proximidade do órgão central do serviço profilático. Esta corrente embasava sua postura nas vantagens que adviriam da localização central e no fato de não haver razão científica que justificasse o distanciamento geográfico das crianças ali internadas. Alegavam também que a localização urbana possibilitaria melhor assistência médica, conforme ficara evidenciado através da experiência do Asilo Santa Terezinha em São Paulo. Durante seus nove primeiros anos, o berçário dessa instituição esteve localizada fora da Capital, nesse período verificou-se um alto nivel de mortalidade infantil, situado em torno de $55 \%$ dos recém-nascidos. Após sua transferência para a zona urbana, e mantendo o mesmo padrão de serviços e organização, esse índice foi baixando, igualando-se ao das demais creches existentes em São Paulo. Esse fato pôs abaixo a crença até então em vigor de que os filhos de hansenianos teriam menor resistência que outras crianças ${ }^{10}$.

A principal vantagem apresentada pela localização urbana era a da possibilidade da integração social dos internos. As crianças teriam, ao menos no plano teórico, maiores possibilidades educacionais, posto que poderiam completar seus estudos em estabelecimentos fora

9. Nelson de Souza Campos foi importante hansenólogo paulista, trabalhou no Departamento de Profilaxia da I epra escreveu importantes trabalhos sobre lepra na infância.

10. O Asilo Santa Terezinha dispunha de duas unidades: a primeira, situada na zona urbana. era destinada aos recem-nascidos. Fistes posteriormente eram enviados para a segunda unidade, distante da Capital e localisada próxima a cidade de carapicuiba. 
do Preventório; teriam ainda possibilidade de acesso ao lazer, o que aliás era previsto no regimento interno. Desta forma, pretendia-se que com a localização urbana minorasse a exclusão da criança do meio social, e que as pessoas viessem a se acostumar com a idéia de convivio com "filhos de leprosos".

Contudo, apesar de todas as vantagens apresentadas pela localização urbana, de não haver risco de contágio, e de ser importante a corrente existente entre hansenólogos que apoiava tal medida, o procedimento adotado foi exatamente o oposto. Ao analisarmos a localização dos 27 Preventórios existentes em 1948, ficou evidenciado que a prática da época era a de construilos em locais afastados dos centros urbanos. Esse fato contribuía para reforçar, aos olhos da população, a idéia do perigo de contágio e da necessidade da segregação.

A análise dos dados existentes sobre a localização dos Preventórios demonstrou não haver uma homogeneidade com relação ao padrão adotado para sua construção, porém a média encontrada foi de 12 quilômetros de distância dos centros urbanos.

Quadro $n^{\circ} 1$

\section{LOCALIZAÇÃO DOS PREVENTÓRIOS EM RELAÇÃO ÀS CIDADES}

\begin{tabular}{lcr}
\hline LOCALIZAÇÃO & NÚMERO & $\%$ \\
\hline & 1 & 3,8 \\
Zona Urbana & 4 & 11,5 \\
Periferia da cidade & 22 & 84,7 \\
Fora do perimetro urbano & 27 & 100,0 \\
\hline TOTAL & & \\
\hline
\end{tabular}

Fonte: Dados extraidos de SOUZA CAMPOS, N. \& BECHELLI, L, M,. 1948 e SALOMÃO, A. 1948

O quadro acima evidencia, mais uma vez, que o preconceito existente com relação à doença fazia com que crianças sadias fossem banidas do convivio com a sociedade, apenas por carregarem seu estigma. Contudo, é interessante destacar que essa postura era, de certa forma, endossada pelo próprio grupo que detinha o saber científico e que foi implantada, apesar da consciência de que tanto a localização de Preventórios em zona urbana, como a convivência social dessas crianças, não acarretariam nenhum risco de contágio.

\section{OS PREVENTÓRIOS PAULISTAS: SANTA TEREZINHA E JACAREÍ}

São Paulo, apesar do grande número de doentes internados, teve apenas dois locais para o internamento dos filhos sadios: o primeiro, o Asilo de Santa Terezinha, foi fruto da 
iniciativa privada; e o segundo, Preventório de Jacarei, foi construído e mantido pelo governo estadual.

Desde o início da década de vinte, a Associação Santa Terezinha do Menino Jesus se preocupava com as crianças filhas de hansenianos. Em 1922, graças à doação do Dr. Celestino Bourroul, a Associação passou a possuir um grande terreno no bairro da Lapa, onde pretendia construir um Asilo-Escola. Entretanto, esse plano foi barrado pelo Serviço Sanitário que alegou ser a localização do terreno muito central para os fins propostos. No ano de 1926, a Associação adquiriu um terreno de $145.000 \mathrm{~m}^{2}$ no município de Carapicuiba, situado no quilometro 23 da Estrada de Ferro Sorocabana, e o projeto foi idealizado pelo engenheiro Álvaro de Salles Oliveira.

Para custear parte do projeto, o terreno da Lapa foi loteado e vendido, o restante da verba necessária para a edificação das construções foi arrecadada através de campanha de levantamento de fundos, a "Campanha Humanissima", realizada por Julio de Mesquita através do jornal O Estado de São Paulo. Em fevereiro de 1926, esse jornal abriu uma lista de contribuições populares, que arrecadou quase toda a verba necessária para a obra.

Em 8 de setembro de 1927 foram inaugurados quatro pavilhões, e as primeiras crianças foram recolhidas. Desde seu início, o Asilo-Escola foi dirigido por Margarida Galvão, cuja trajetória de vida passa a estar intimamente ligada a essa obra.

Com o tempo, foi necessário repensar o problema, devido a alguns inconvenientes, como o acarretado pela distância a ser percorrida entre os asilos e a creche:

"A distância em que se acham localizados os Asilos-Colonia, alguns a mais de 400 quilómetros da Capital, motiva a demora da chegada daquelas crianças à Instituição, demora essa que expõe a saúde e ulterior desenvolvimento dos recém-nascidos a graves danos (...). Acresce notar-se que o transporte feito por estradas de ferro, caminhões, etc, nem sempre atende e provê à necessária proteção contra resfriamentos e infecções ..." (BARROS, 1943)

Devido a isso, foi fundado, em 1937, o berçário "Carolino Motta e Silva" na Capital, situado à Avenida Água Branca, 147. Este só atendia os recém-nascidos, que ali permaneciam até 3 anos de idade; mais tarde foi transferido para um local maior, localizado à Rua Morato Coelho, no bairro de Pinheiros. 
Ilustração $n^{\circ} 1$

\section{CRIANÇAS DO ASILO DE SANTA TEREZINHA}

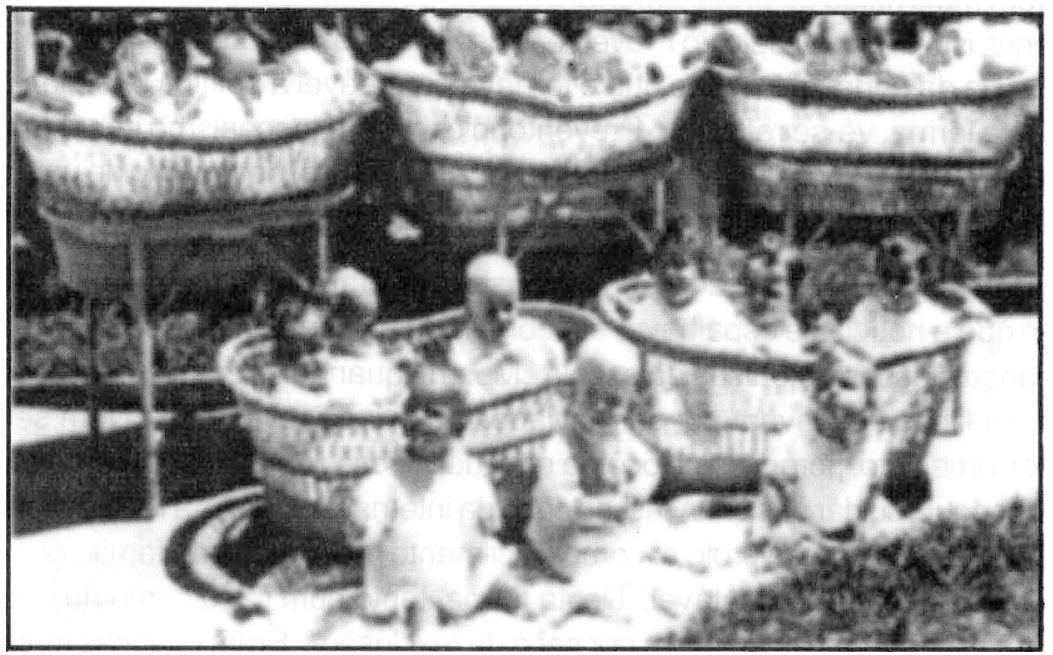

Fonte: Arquivo da Divisão de Hansenologia e Dermatologia Sanitária

Com o início da internação em massa dos portadores de hanseniase, e sabendo-se que aumentaria grandemente o número de menores que ficariam em abandono devido ao internamento dos pais, o Estado de São Paulo incluiu em seus planos a construção de um Preventório que ficaria subordinado à Inspetoria de Profilaxia da Lepra. Estudos foram feitos, e o Preventório acabou por ser instalado no prédio de um antigo ginásio, o "Nogueira da Gama", na cidade de Jacarei. O prédio foi adaptado e inaugurado em 7 de julho de 1932.

Desde o inicio recebeu grande número de crianças de todas as idades; mas depois foi feito um acordo com o Santa Terezinha, que manifestava preferência pela internação de recém-nascidos e crianças do sexo feminino. Desta forma foi realizada uma troca interna: 80 meninos maiores de 12 anos que estavam no Santa Terezinha foram enviados para Jacarei, que por sua vez lhe enviou as crianças menores que ali estavam internadas. A partir de então, ficou mais ou menos definido que a primeira instituição ficaria responsável pelos recém-nascidos, e que ao crescerem, os do sexo masculino seriam enviados para Jacarei, sendo que as do sexo feminino poderiam ali continuar. 
Para Jacareí também eram encaminhadas as crianças egressas dos asilos-colonia com alta condicional.

\section{O DRAMA DA CRIANÇA INTERNADA}

Como já foi visto, em São Paulo existiam apenas dois locais de internação, o Asilo de Santa Terezinha e o Preventório de Jacareí, ambos com trajetórias semelhantes e muitos pontos em comum. Contudo, é através da análise do funcionamento do segundo que tem-se uma imagem mais nítida do procedimento adotado pelos hansenólogos paulistas com relação ao menor, isto devido ao fato do Preventório de Jacareí estar subordinado ao Departamento de Profilaxia da Lepra, o D.P.L. o que o tornava permeável à política exercida por aquele órgão. Desta forma, vê-se refletir no Preventório o mesmo mecanismo imposto aos asiloscolonia, ou seja, um grande cuidado com a tarefa profilática em detrimento de uma visão mais humanista com relação aos internos, ainda que estes fossem crianças e saudáveis.

Via de regra, a internação de um dos pais acarretava a chamada "explosão familiar", pois assim que a noticia se espalhava, era comum que ocorressem perdas de emprego ou que as crianças fossem expulsas da escola. Mesmo quando apenas um dos genitores era internado, os filhos acabavam por ser enviados para um Preventório. Nem sempre esse processo era imediato, porém o que ocorria era que, no caso da mãe ser internada, o pai nem sempre conseguia cuidar das crianças, no caso da internação do pai, a mãe acabava por não ter condições de sustentar a prole e, como dificilmente havia ajuda de familiares, a situação acabava por se tornar insustentável. Desta forma, tanto num caso como no outro, o único espaço para essas crianças acabava por ser o da "exclusão". Eram crianças marcadas que, praticamente, não dispunham de outro local para ir a não ser o Preventório.

O fato dos Preventórios estarem subordinados do ponto de vista técnico ao Serviço de Lepra, acabava por criar estreitos vínculos de dependência, uma vez que após o ingresso das crianças, o controle clínico-dermatológico era por ele realizado. No caso de Jacareí a vinculação era total, uma vez que o mesmo havia sido criado pelo Estado e era diretamente subordinado à direção do D.P.L.

A dependência observada em Jacareí transformou esse Preventório numa espécie de continuidade do "mundo" criado pelo D.P.L.. A reprodução de algumas práticas observadas nos asilos pode ser observada, em especial, durante o período Salles Gomes na direção do D.P.L. o que marcaria seu funcionamento até o final do período de isolamento compulsório, no final da década de sessenta. Ao analisarmos o item direção do Regimento Interno dos Preventórios, verifica-se que o procedimento aconselhado era que:

"A escolha dos dirigentes deve pois revestir-se de todo o cuidado e atenção, obedecendo ao mais rigoroso critério de seleção"

A centralização das estruturas de controle, e os critérios para a escolha da direção, deixam claro que o objetivo principal a ser levado em conta não repousava na adequação 
do perfil do profissional com as especificidades do cargo, e sim no da homogeneidade de procedimentos e subordinação ao controle do Serviço Profilático:

"O diretor era o Seu Guido Martins Moreira. Ele era dentista, mas ele só funcionava como diretor. Ele era cunhado do Dr. Salles Gomes. A irmã dele, dona Gilda, era casada com o Sales Gomes. E foi isso aí. O seu Guido não era bom prá nós, ele era muito frio, sabe ${ }^{10}$.

À semelhança do que ocorreu no D.P.L., a direção nomeada logo no início do funcionamento do Preventório se perpetuou até fins da década de 40 , conforme pode ser verificado nas assinaturas dos documentos. O fato da direção do Preventório de Jacareí ter sido exercida por pessoa de confiança da direção do D.P.L. proporcionava a seu diretor liberdade de atuação, sem que fosse admitido o questionamento dos métodos adotados:

"E as outras meninas todas queriam sair. Porque era um regime assim.... muito rígido. Muito rígido mesmo. Eles puseram uma govemanta, nossa! que parecia uma govemante da Gestapo. O vigilante dos meninos também era terrivel. E as crianças lá não eram crianças assim ... Eram crianças que vinham da roça. Eram humildes, assim... até bobinhas, não havia necessidade desse regime bravo, desse regime duro."(ANA, 1992)

\section{A SEPARAÇÃO DA FAMILIA}

A estruturação do modelo profilático visava proteger o menor, porém na realidade fazia com que crescesse sem nenhuma, ou com poucas lembranças e informações sobre sua origem, pais e grupo familiar.

Muitas das crianças, por terem sido internadas ao nascer, não dispunham de recordação alguma. Outras, por terem sido internadas com mais idade, conservaram suas lembranças, inclusive as do momento da internação.

$O$ ingresso no Preventório já se configurava num ato de violência na vida dos internos, que na maior parte das vezes nem tinham consciência do que estava ocorrendo em suas vidas:

"Até então nós não tínhamos sido examinados. Daí eles foram nos buscar, viemos para Av. Dr. Arnaldo. Foi constatado que minha mãe também estava doente, mas ela era forma $T$., enquanto que meu pai era $L$. Minha mãe foi internada com meu pai no Departamento, e nós passamos uma noite lá no Departamento, depois é que nos levaram para o Preventório. Ficamos lá sozinhos, meu irmão tinha só um ano e meio e chorava, chorou a noite toda chamando a mãe, deu um trabalho ... . Era ... nem sei! Tem coisas que a gente não querguardar. Eu tinha só 5 anos" $"$.

11. Quando a depoente fala em Departamento se refere ao Departamento de Profilaxia da Lepra. Quando um doente era diagnosticado, ou capturado, na parte da tarde se nào houvesse viatura para removê-lo para um dos asilos, então o mesmo era alojado em uma das acomodações pertencentes ao D.P.L. e enviado pela manhã para seu local de internamento. Estes alojamento ficavam na Av. Dr. Arnaldo, ao lado da Faculdade de Saúde Pública da USP. 
O fato das crianças serem criadas longe de seus pais gerava com freqüência uma série de problemas decorrentes da separação, agravados pelas dificuldades existentes para a realização de visitas. A legislação, os congressos médicos, e as normas internas do Serviço Médico Oficial alegavam motivos profiláticos para justificar as características da separação imposta.

Esse assunto foi normatizado através de uma Resolução baixada pela Federação das Sociedades de Assistência dos Lázaros e Defesa Contra a Lepra (FSAL) em 1942, e que passaria a regular os Preventórios mantidos pelas Sociedades a ela filiadas. Apesar dos Preventórios de São Paulo terem tido características próprias, na prática cotidiana não havia discordância quanto ao estabelecido no Regulamento estabelecido pela FSAL.

A análise desse Regulamento permite verificar a ótica da instituição sobre o assunto, posto que estabelece que toda e qualquer comunicação entre menores internados só seria realizada mediante a autorização da direção do leprosário, do Serviço de Lepra, ou da autoridade sanitária local, e de acordo com a diretoria da Sociedade mantenedora do Preventório.

A orientação oficial dos Preventórios era de que fosse desestimulado qualquer tipo de vínculo afetivo com a família. Desta forma, as visitas e a correspondência eram dificultadas. O Regulamento, em seu artigo IV, estipulava que:

"Serão evitadas, o mais possivel, as comunicações pessoais entre o menor internado e o hanseniano, internado ou não" (ARAUJO, 1942)

As visitas de parentes eram ainda dificultadas pela burocracia e pelo zelo profilático, sendo que todo aquele se dispusesse a fazer visita seria enquadrado na categoria de "comunicante" e como tal teria que se submeter a exames periódicos, como se evidencia no artigo VII do Regulamento:

"As visitas aos educandários, quer de parentes sadios quer de pessoas estranhas, deverão ser sempre efetuadas em dias e horas previamente fixados, sendo obrigatória, para os comunicantes, a apresentação da respectiva carteira.. (ARAUJO, 1942)

Todos os que se dispusessem a realizarem visitas seriam, obrigatoriamente, enquadrados na categoria de "comunicantes" e, como tal, teriam que ser fichados e se submeter a exames periódicos nos dispensários do D.P.L.

Se os Regimentos e a documentação oficial permitem conhecer a postura do Serviço Profilático sobre a questão, a análise dos prontuários nos permite recuperar um outro ângulo do problema, o da separação vista sob a ótica dos pais. As cartas escritas pela mães solicitando permissão para ver os filhos, ou pedindo notícias, ou solicitando que, ao menos, pudessem receber uma fotografia da criança. As dificuldades enfrentadas para ter acesso a 
algum informe sobre as crianças internadas, nos dão a medida do drama decorrente da situação vivida. Os encontros eram raros, e quando ocorriam eram sempre vistos como uma concessão especial, e não como uma prática de direito.

\section{CENSURA DE CARTAS}

A correspondência endereçada às crianças do Preventório, assim como as cartas que estas escreviam, eram abertas e censuradas, e só eram entregues aquelas que a instituição permitisse. Devido a isso são numerosas as cartas cujos originais, ou cópias, foram parar nos prontuários pertencentes aos pais dessas crianças. Muitas dessas trazem anotações dizendo estar o original no prontuário do menor, ou então que uma cópia foi enviada para o Preventório.

De acordo com depoimento colhido, essa censura era conhecida por todos, pais e filhos. Se escrevessem reclamações ou dessem notícias sobre descontentamentos, as cartas seriam censuradas. Esse procedimento, usual em São Paulo, era também adotado em outros Estados, como relata um estudo sobre os Preventórios em Minas Gerais:

"As nossas cartas, quando a gente recebia, elas já ... já tinham sido abertas, lidas e as nossas também, quando ia, elas tinha sido lida, aberta (...) e conforme fosse o que tivesse escrito, não ia. Não ia, não chegava (..)"(GOMIDE, 1991)

A criança internada servia também como uma importante peça na estratégia de poder do D.P.L.. As fugas eram comuns e, se um pai que estivesse internado fugisse de um dos Asilos, a criança, mesmo que tivesse condições de ser liberada, ficava como uma espécie de refém nas mãos do Serviço Profilático. Os funcionários que trabalhavam nos Preventórios por vezes acabavam por auxiliar o menor a burlar o controle estabelecido, tornando possivel o acesso a informações vindas de fora, como relata a depoente acerca de seu marido, também criado em Jacarei:

"Então era assim. Sabe como nós faziamos? Meu marido tinha muita amizade como marido da cozinheira. Então a carta vinha para a casa dela. Dai eles ajeitaram as coisas, amumaram um contato com o pai, escreviam e ela trazia a carta escondida prá ele lá no Preventónio. E assim ele começou a se comunicar com o irmão que fugiu. (...) Quando o irmão mais velho fugiu, ele mandava as cartas para essa casa. Ele havia conseguido acharo pai. (ANA, 1992)

O relacionamento com pessoas de fora da estrutura do Preventório era um privilégio a que poucos tinham acesso, ainda que essa pessoa fosse o próprio pai, e que poderia significar a diferença entre ter, ou não, o direito a correspondência:

"Nós escreviamos cartas, mas eu tinha uma amiga muito boa no ginásio, e as cartas iam para a casa dela. As cartas não vinham com o meu nome. Eu tinha outro nome, e ela já sabia que era para mim.” 
A ausência de contato entre pais e filhos e a falta de notícias de ambos os lados durante anos contribuiam para que o genitor asilado se transformasse em alguém estranho, com quem não havia muito a partilhar.

Essa estrutura, se por um lado distanciava a criança de seus familiares, por outro também privava os pais das notícias sobre os filhos, uma vez que não era procedimento usual dessas instituições manter os pais informados sobre a vida do interno.

\section{A VIDA NO PREVENTÓRIO}

A austeridade da vida dentro do Preventório fica evidenciada ao se analisar o cotidiano dessas crianças, o que se torna possivel a partir da documentação existente e, em especial, dos depoimentos dos ex-internos. Ao se analisar itens de importância para o universo infantil, tais como alimentação e lazer, pode-se verificar o tipo de estrutura montada nesses estabelecimentos.

"Lá era muito pobre, a alimentação era muito pobre. (...) Nós não tínhamos esporte, recreação nada. Depois que eu sai é que começou a melhorar um pouco, mas enquanto eu estive lá não tinha nada. (...) No Natal a gente ganhava brinquedo. E a gente comia frango. Também era só no Natal. la um pessoal de São Paulo, umas senhoras, Acho que alguma associação, e eles levavam brinquedos para nós... Todo ano."(ANA, 1992)

A ordem e a disciplina impostas visavam garantir o "bom funcionamento" da instituição do ponto de vista profilático, ainda que isto implicasse num custo social a ser pago pelos internos.

Os hansenólogos paulistas que escreveram sobre Preventórios se posicionavam favoravelmente à interação das crianças internadas com a sociedade. Acreditavam ser possivel a diminuição do estigma apenas através da participação destas em atividades sociais:

"A freqüência à igreja, ao cinema, comemorações públicas, festividades, etc., acabam por completar a readaptação dos menores, diminuindo e banindo o estigma que pesa sobre eles" (CAMPOS \& BECHELLI, 1948)

Em Jacarei havia poucas oportunidades de lazer e dentre elas destaca-se a ida ao cinema. Os internos eram levados semanalmente para assistir à matinê, e essas saídas constituiam o ponto alto da semana e, por serem aguardadas com ansiedade, funcionavam como poderoso instrumento de punição àqueles que infringissem alguma norma:

"Quem fizesse qualquer coisinha durante a semana não ia à matinê."

Se por um lado tinha-se toda a herança de discriminação herdada, esta era ainda reforçada pela postura adotada pelo D.P.L., que pregava sobre o "perigo do contágio" e 
"necessidade da exclusão total". Desta forma, o simples fato de um grupo de crianças comparecer em locais públicos acabava por resultar em medidas discriminatórias, e não se tem notícia de terem sido realizadas ações educativas concretas que permitissem a modificação das concepções da população com relação a essas crianças:

"Mas no cinema nós éramos discriminados. Porque, na matinê, o pessoal da cidade já sabia, ninguém sentava perto de nós. Então já tinha um lugar certo, só para o pessoalzinho do Preventório. A gente sabia disso"(ANA, 1992)

Com relação aos estudos, o Regimento Interno dos Preventórios dispunha de cinco artigos específicos. O parágrafo único do artigo 23, que dispunha que: "No caso de manifestar qualquer internado pendor para as letras, artes ou ciências, a direção superior providenciará sobre a sua instrução fora do estabelecimento, custeando todas as despesas". Entretanto, verifica-se ter havido grande distanciamento entre o disposto e o praticado, na medida em que as oportunidades de ensino eram extremamente limitadas e que os internados acabavam por ter acesso apenas ao curso primário, que era ministrado dentro da instituição. Se oportunidades de ensino fora do Preventório já eram restritas, observase que a situação era ainda agravada pelo não interesse da instituição em prover o mínimo necessário para o prosseguimento dos estudos dos internos.

"Nós estudávamos lá mesmo. Para quem tinha oito anos tinha grupo escolar dentro do preventório, nós não saíamos fora. Ali tinha do $1^{\circ}$ ao $4^{\circ}$ ano. (...) Eu tive mais sorte porque eu consegui estudar. Não tinha nada de ginásio do Estado. Tudo era particular. O ginásio da cidade tinha que oferecer duas vagas de graça e uma vaga foi oferecida para o Preventório (.....) e eu que fiquei com vaga e pude estudar. (...)mas era uma dificuldade, porque eles não me davam livros, não davam cadernos... Era uma dificuldade. Quem me ajudava muito era uma senhora que depois me batizou lá, sabe ela era uma funcionária, então ela me ajudava.(ANA, 1992)

A estrutura de funcionamento montada no Preventório de Jacareí, evidencia o distanciamento existente entre o texto do Regimento Interno, que dispunha sobre a viabilida: de da continuidade dos estudos, e as dificuldades encontradas pelas crianças para conseguir romper com o modelo: Enquanto que em Minas Gerais, por exemplo, havia a possibilidade dos internos realizarem cursos profissionalizantes, em São Paulo a realidade era outra, uma vez que a própria direção do Preventório era a responsável pela não continuidade dos estudos, ou pelo menos pela não qualificação profissional dos internos: ${ }^{12}$

12. Na organização dos Preventórios em Minas, havia o "Aprendizado Técnico Profissional" situado em Belo Horizonte, para onde eram enviados os meninos que "demonstravam pendores para outras profissões". Ver SALOMÃO, A. - Dados Epidemiológicos sobre 725 crianças filhas de hansenianos fichadas no Preventório de São Tarcísio em treze anos de funcionamento. In: Memória do V Congresso Internacional de Lepra, 1948, p. 739. 
"Tinha escola profissional na cidade. Veja só. E a escola profissional pediu que mandassem os meninos para a escola. Inclusive meu marido foi para a escola profissional. Mas você sabe que tinha um sitio que pertencia ao Preventório, mas você vê como eles eram .... O diretor tirou os meninos da escola profissional para trabalharem no sitio, na lavoura, e eles deixaram de estudar." (ANA, 1992)

llustração n. ${ }^{\circ} 2$

\section{CRIANÇAS TRABALHANDO NO CAMPO}

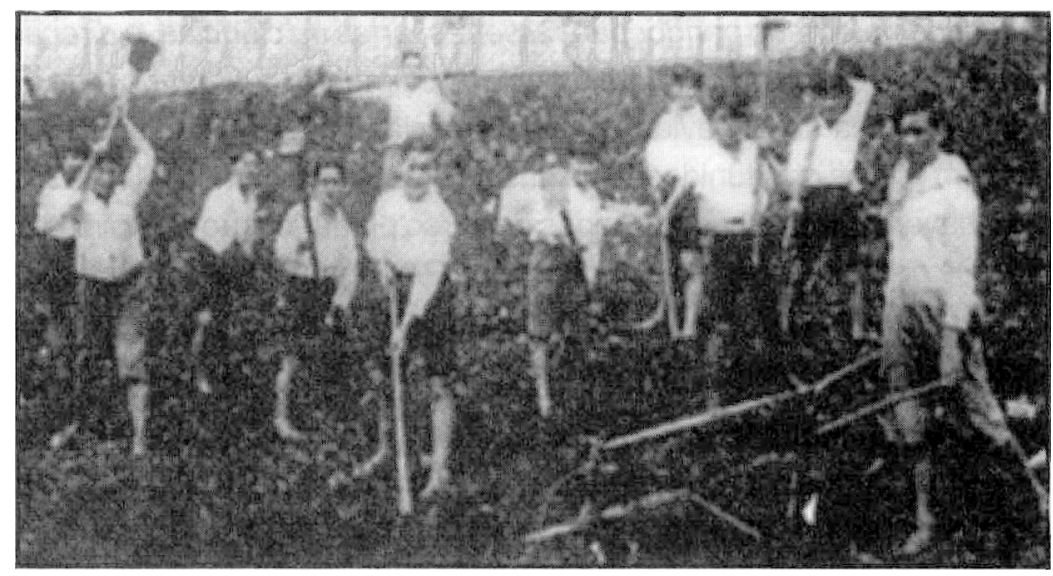

Fonte: Arquivo da Divisão de Hansenologia e Dermatologia Sanitária

O trabalho era considerado como um importante instrumento disciplinador, fator destacado por Nelson de Souza Campos que aconselhava que se o trabalho fosse atribuido

“... ao maior número possivel de internados, do sexo feminino e masculino, fazendo-os exercer as funções que thes são adequadas (...) pois trabalhando tornam-se mais dóceis $e$, por conseguinte, será mais fácil a administração ..." (SOUZA CAMPOS \& BECHELLI, 1948)

O Regimento Interno dos Preventórios colocava um limite de idade para o inicio dessa atividades, que eram vistas como "aprendizagem"; desta forma, assim como nos asilos-colonia, o trabalho fazia parte do cotidiano dos internos, como podermos verificar no Artigo n. 31 que estipulava que "Os internados maiores de 12 anos prestarão pequenos serviços ao Preventório a título de aprendizagem, uma vez julgados aptos a fazê-lo, sendo aproveitado o pendor natural que manifestarem por esta ou aquela tarefa". Contudo, o limite de idade não era respeitado, e as crianças começavam a trabalhar bem cedo, como acontecia no Preventório de São Tarcísio, por exemplo: 
"Os internados do sexo feminino se ocupam dos serviços de copa, cozinha geral e dietética, limpeza do estabelecimento, arranjos domésticos gerais, costuras, remendos, bordados, etc. Os do sexo masculino, atingida a idade de 8 anos, se incumbem de leves trabalhos de campo, jardinagem, cuidado dos animais domésticos, horta, pomar, etc. (SALOMÃO, 1948)

O trabalho exercido pelos internos representava uma forma de diminuir o ônus da instituição, visto que apenas as crianças maiores de 16 anos receberiam remuneração pelos serviços prestados. O Regimento Interno, em seu artigo 32, estipulava que a remuneração deveria ser calculada em torno de $30 \%$ do valor a ser pago "por trabalho idêntico a empregado estranho". Contudo, poucos eram os empregados necessários, visto que a maior parte dos trabalhos acabava sendo desempenhada pelos próprios internos:

O tipo de formação educacional permitida no Preventório condicionou as possibilidades e oportunidades de vida que os menores tiveram ao sair da instituição. Desta forma, as meninas acabavam por se tornarem empregadas domésticas, e os meninos saíam sem capacitação, a não ser para os trabalhos agrícolas ou para o exercício de tarefas que não necessitassem qualificação.

\section{A VOLTA PARA O "MUNDO DOS SADIOS"}

Sair da instituição nem sempre se constituia numa tarefa simples para o interno, até mesmo para os que atingissem a maioridade, em especial porque uma boa parte deles não tinha para onde ir. Como já visto, o tipo de estrutura montada favorecia o distanciamento familiar e a falta de uma formação profissional limitava as chances de que o egresso pudesse prover sua própria manutenção. Essa situação ainda era agravada pelo tipo de vida a que haviam sido submetidos, em que o distanciamento do mundo fazia com que eles não soubessem como viver fora dos muros da instituição:

"Mas era difícil sair de lá. Sabe porque?, os que tinham pai e mãe doente não tinha como sair. Lá eles não davam uma profissão. A gente só fazia o curso primário." (ANA, 1992)

Para poder sair, essas crianças tinham que vencer uma série de dificuldades, e dentre elas destaca-se o problema da documentação. As crianças nascidas nos asilos-colonia, durante muito tempo, tiveram essa informação em sua certidão de nascimento. Somente a partir de junho de 1940 é que a direção do D.P.L. enviou circular aos diretores clínicos dos asilos para que no registro de nascimento não constasse o nome da instituição e tão somente o nome do municipio onde esta estivesse inserida. As crianças que eram recolhidas aos Preventórios já com mais idade nem sempre dispunham de certidão de nascimento e, a julgar pela documentação consultada no Arquivo de Prontuários, esta nem sempre era providenciada. Isto pode ser verificado 
através do histórico da menor R.C.G., aliás um caso entre muitos. Após transcorrer longo período entre a solicitação de permissão para a saída realizada pela mãe da menor e de todas as exigências terem sido cumpridas, ainda assim ao sair a criança não dispunha de documentos:

São Paulo, 28 de maio de 1942

\section{$n^{\circ} 2.241$}

Senhor Chefe de Estação da Luz:

Pelo presente, levo ao conhecimento de V.S., que R(.......), que se destina a Monte Alto acompanhada pelo Sr. Paulo Vasconcelos do Espirito Santo, guarda desde Departamento de Profilaxia da Lepra, não possui documento algum, por se tratar de menor procedente do Asilo Santa Terezinha, onde estava internada.

Atenciosamente

\section{Dr. Nelson Solano Pereira}

Subdiretor

(PRONTUÁRIO N. 854 - ARQUIVO DE HANSENÍASE DO ESTADO DE SÃO PAULO)

É interessante ressaltar que, assim como ocorria com o doente internado, também as crianças, quando saíam o Preventório, iam acompanhadas por um guarda e não por uma professora ou assistente social. Esse fato contribuía para consolidar, na população, a "sensação perigo" com relação a um desses internos.

Mesmo que a criança tivesse um dos genitores, ou outro parente, disposto a retirála, e que provasse ter condições para mantê-la, ainda assim ela poderia ter sua saída vetada pelo D.P.L., que possuía poderes para tal. O Regimento Interno norteava os procedimentos a serem adotados nessas ocasiões. Entretanto, em razão deste não prever uma série de questões, que permeavam o cotidiano dos internos, foi formada uma Comissão para que elaborasse um documento específico definindo e norteando o assunto que mesmo assim continuou não sendo pacífico. A questão da saída arrastou-se por muitos anos e era tão séria que acabou por se constituir no assunto principal da $235^{\text {a }}$ Sessão Ordinária da Sociedade Paulista de Leprologia, realizada em 19 de dezembro de 1955, na qual discutiu-se o "Relatório da Comissão sobre o Regulamento que disciplina a entrega dos menores". Nela foi proposto, e aceito pelos presentes, que só poderia ser permitida a saída de crianças portadoras do exame de Mitsuda Positivo, ou seja, de crianças que fossem possuidoras de resistência natural à doença. O estranho em tudo isso é que essa reunião ocorreu em 1955 , 
numa época em que a recomendação internacional era a de que não se internassem nem mesmo os doentes, visto que poderiam ser tratados normalmente em dispensários. Também estranha-se que, apesar disso, o Estado de São Paulo resolvesse continuar mantendo crianças fechadas numa instituição, sem serem portadoras de doença alguma, mas apenas por pertencerem a aquela percentual da população sem resistência natural.

Como se não bastasse a postura médica, a saída da criança ainda estava condicionada a fatores burocráticos: por exemplo, os comunicantes arrolados em seu prontuário tinham que estar, todos eles, com os exames periódicos em dia, caso contrário ela continuaria internada, ou seja, o interno responderia pelos atos de terceiros. Contra essa regra manifestou-se o Dr. J. Barros, fazendo registrar sua postura em Ata, durante a 235 Sessão Ordinária da Sociedade Paulista de Leprologia:

"Então uma criança vai pagar com sua liberdade, se o comunicante não se submeter ao exame. Isso é importante do ponto de vista profilático, mas não devemos condicionar a saida ao exame do comunicante".

A estrutura montada pela instituição fazia com que as crianças, ao saírem do Preventório, estivessem totalmente despreparadas para viver fora de seus muros. Sabiam ser portadores de um estigma e, aos poucos, iam tendo que aprender as formas de ocultamento de um passado que, se descoberto, só poderia prejudicá-las. Dessa forma, as relações sociais tendiam a ser dificultadas, uma vez que manter uma relação intima com alguém poderia significar maior vulnerabilidade sobre seu "segredo". As próprias instituições de internamento tinham noção desse problema e, inclusive, procuravam orientar seus egressos sobre a forma de proceder para o ocultamento:

"Os egressos de nosso Asilo lutam quase sempre com grandes dificuldades na sua vida, pelo fato de serem filhos de doentes de lepra. Essa dificuldade toma vulto e é quase insuperável, inúmeras vezes, quando esses egressos não podem ocultar sua condição de filhos de leprosos." (GALVÃO,1940) ${ }^{13}$.

Essa discriminação permeava toda a sociedade e podia ser encontrada mesmo em grupos tidos como intelectualizados ou melhor informados. O depoimento abaixo revela que a simples menção de ter estado num Preventório era suficiente para gerar medidas de exclusão, como ocorreu numa das escolas públicas mais tradicionais da cidade de São Paulo que, ao saber que ao analisar a documentação da canditada e verificar que ela havia estado num Preventório, exigiu laudo médico que atestasse não ser portadora de "lepra".

13. Carta enviada pela Presidente do Asilo Santa Terezinha ao D.P.L., em 15 de junho de 1940, publicada em "Cinqüenta anos do Mal de Hansen". Jornal da Tarde, São Paulo, 18/08/73. 
"Dai eu consegui entrarna Escola Caetano de Campos, mas daíquando eles souberam que eu havia estado em Jacarei eles exigiram um exame especializado sabe. Você vê ... eu havia ficado 20 anos em observação, mas mesmo assim eles exigiram. Foi feito um exame e participaram três grandes médicos, o Dr. Nelson de Souza Campos, Lauro de Souza Lima, aliás ele foi um homem extraordinário (....) (ANA, 1992)

A exigência realizada pela escola pode ainda ser, de certa forma, entendida como admissivel, entretanto chega a causar estranheza o fato de que após vinte anos de observação realizada pelos próprios médicos do Departamento de Profilaxia da Lepra, esse serviço ao invés de simplesmente fornecer $\mathrm{o}$ atestado solicitado, baseado no prontuário existente, tenha cumprido o ritual de praxe reunindo três especialistas para a elaboração de um diagnóstico. Esse tipo de procedimento evidencia que toda a criança "fichada" por ter tido genitores doentes, ainda que possuísse baciloscopia negativa, estivesse em constante observação clínica durante longos anos, ainda continuava a ser considerado, pelo Serviço Profilático como alguém clinicamente "suspeita".

A concepção alicerçada na sociedade, fazia com que o fato de ser um ex-interno significasse, inclusive, restrições nas relações afetivas e na escolha do parceiro

"Também tinha problema para a gente namorar, nós tínhamos medo. A gente não tinha coragem de contar. Então a gente não namorava ninguém, tínhamos medo de falar, medo que descobrissem nosso passado. (...) Depois que ela saiu ela arrumou um namorado, mas ela sofreu porque ele ficou sabendo. Não tínhamos nada mas éramos pessoas marcadas. Naquela época ficava, não podiamos nem sonhar que descobrissem (...) . Acabei casando com um rapaz por esse motivo. Porque eu achava que só daria certo com alguém que também tivesse sido de lá; que tivesse tido o mesmo problema. Tanto é que meu marido também é de lá." (ANA, 1992)

Ao analisarmos o histórico de filhos de hansenianos que passaram por Preventórios verificamos que o tipo de política profilática adotada pelo Estado acabou por dar origem a um grupo social que, embora fosse sadio, partilhava da mesma herança estimagmatizante dos portadores de hanseniase. O fato de ter passado por um Preventório constituia por si só um fato de descrédito social. Desta forma, as possibilidades de inserção no "mundo dos sadios", tais como chances de conseguir empregos, constituir relacionamentos sociais ou afetivos, estavam intimamente vinculadas a capacidade de ocultamento de seu passado e da manipulação de sua identidade real. Desta forma, os egressos dos Preventórios acabaram por formar grupos em que os membros eram provenientes da mesma categoria, ou seja exinternos. Esse procedimento, se por um lado representava, para o membros do grupo, alguma forma de proteção, segurança ou compreensão, por outro contribuía para que, mesmo fora dos muros da instituição, a segregação se fizesse presente. 
Em suma, a análise das trajetórias percorridas pelos pais doentes e filhos sadios acabaram por ser semelhantes, posto partilharem de idênticos mecanismos de estigmatização e marginalização.

\section{FONTES}

Arquivo Médico de Hanseniase do Estado de São Paulo - AMHSP

Prontuários médicos

Cartas de doentes

Entrevistas - com egressos de Preventórios

\section{REFERÊNCIAS BIBLIOGRÁFICAS}

ALBUQUERQUE, J.A. Guillon: instituição e poder: a análise concreta das relações de poder nas instituições. $2^{\text {a }}$.ed., Rio de Janeiro, Graal, 1986.

ARAUJO, H.C. Das relações entre as crianças internadas nos preventórios e seus pais, isolados ou não. Rev. Bras. Leprol.(1):10, 1942.

ATA da 235a . Sessão Ordinária da Sociedade Paulista de Leprologia. Rev. Bras. Leprol., $(1 / 4): 23,1955$.

BARBOSA, R. Higiene escolar. In: Anais Congresso Médico Brasileiro, $9^{\circ}$ São Paulo, 1925. Anais, vol 3, 1925.

BARROS, H. A creche Santa Terezinha no biênio 1941-1942. Rev. Bras. Leprol., 11:, 1943.

GOFFMAN, E. Estigma: notas sobre a manipulação de Identidade deteriorada.4 ${ }^{a}$. ed. Rio de Janeiro, Ed. Guanabara, 1988.

GOMIDE, L.R.S. Órfãos de pais vivos: a lepra e as instituições preventoriais no Brasil: estigmas, preconceitos, segregação. São Paulo, 1991. [Dissertação de Mestrado, FFLCH-USP]

LEMOS, F. Um problema de eugenia. Correio da Manhã, Rio de Janeiro, 10 de novembro de 1939.

MONTEIRO, Y.N. Da maldição divina a exclusão social: um estudo da hanseniase em São Paulo. São Paulo, 1995. [Tese de Doutoramento, FFLCH/USP]

REGULAMENTO interno dos preventórios. São Paulo, 1928. 
SALOMÃO, A. Dados epidemiológicos sobre 725 crianças filhas de hansenianos fichadas no Preventório de São Tarcísio em treze anos de funcionamento. In: V Congresso Internacional de Lepra, 5o, 1948. Memória.

SCHECHTMAN, A. Psiquiatria e infância: um estudo histórico sobre o desenvolvimento da psiquiatria infantil no Brasil. Rio de Janeiro, 1981. [Dissertação de Mestrado UERJ]

SOUZA ARAUJO, H.C. A lepra: estudos realizados em 40 países. Rio de Janeiro, Tipografia Osvaldo Cruz, 1929.

SOUZA CAMPOS, N. \& BECHELLI, L. M. Organização e funcionamento de preventórios. Rio de Janeiro, Imprensa Nacional, 1948.

TIBIRIÇÁ, A.T.R. Como eu vejo o problema da lepra: e como me veem os que o querem manter. Rio de Janeiro, Imprensa Nacional, 1948.

Summary: This work analyses how the compulsory isolation practice of Hansen's disease patients in the State of São Paulo has contributed for the Hansen's stigma affecting people that never had the disease - the case of healthy children of Hansen's disease carriers. The present article discusses how eugenic ideals have contributed for the formation of a medical posture that even despite scientific advances and international recommendations has perpetuated discriminatory and segregational measures against these children. The paper shows how such children ended up by carrying life long "inborn stigma" that has resulted in the hindering of their life possibilities that made them hide their former condition of interns or egresses of preventive centers to compete in society under equal conditions for jobs and the establishment of social relations. It also analyses the life in the preventive centers, separation from the family and the daily life of hundreds of lives shaped within control structures where violence and arbitrariness were practiced in the name of a distorted view of prophylaxis.

Key works: stigmatization; marginality; hansen's disease; preventive centers; health policies 